\title{
Smart University System Based on Wireless Technologies in Kazakhstan
}

\author{
Nurbek Saparkhojayev ${ }^{1+}$ and Rimma Akkozieva ${ }^{2}$ \\ ${ }^{1}$ Director of School of Engineering Management- Head of "IT in Education” Research Lab, Almaty \\ Management University, Almaty, Kazakhstan \\ ${ }^{2}$ Senior Lecturer, University of International Business, Almaty, Kazakhstan
}

\begin{abstract}
The urgency of developing this system arises in connection with the growing needs of universities in Kazakhstan to automate the process of checking attendance, both students and staff; and to make the use of computers more efficiently, especially for students, and to automate the process of controlling doors. Also, an important factor of the application and the use of this technology is the possibility of disposing of one universal card /tag, that will not only use it for the described purposes, but also allows its cardholders to pay for various services provided in the university, where this system is deployed. In addition, the system allows controlling the time of arrival and departure of personnel and automating accrual final salary in accordance with the number of hours worked staff.

In general, the proposed system consists of following modules: module for checking students' attendance; module for checking staff attendance; module for controlling the doors, like opening/closing doors, locking/unlocking doors, mobile application for attendance checking; and module for controlling the use of computers. In addition, all these modules use our own encryption algorithm that secures data processing during the workload of each module.
\end{abstract}

Keywords: RFID technology, NFC technology, encryption algorithm, smart system, education.

\section{Introduction}

Radio-frequency identification (RFID) is a technology that uses radio waves for transferring data from an electronic tag that - called an RFID tag or label, which attached to an object - through a reader for the purpose of identifying and tracking the object. Systems built on RFID technology have been widely used in many different application areas, namely: product tracking through manufacturing and assembly, control of inventory, parking lot access and control, container tracking, ID badges and access control, equipment tracking in hospitals, metro access, etc. [1]. Regarding Near-Field Communication (NFC) technology, it is one of the popular latest wireless communication technologies, and within this technology, communication occurs when an NFC-compatible device is brought within a few centimeters of another NFC device or an NFC tag. NFC technology opens up exciting new usage scenarios for mobile devices [2]. Building smart office [3], smart hospital [4][5] is an nascent trend that encompasses ubiquitous computing concept of Mark Weiser [6] who highlighted the seamless integration of technologies in human lives. Moreover, authors in [7] introduced how RFID technology efficiently can be used for developing a smart system in educational institutions. The motivation of this paper is to emphasize the benefits of using RFID and NFC technologies in developing smart university concept. The developed prototype system [8] describes how emerging technology of RFID can bring in improving security, power conservation, person tracking etc. The rest of this paper is organized as follows: Section II provides motivation for implementing such system with description of some other existing systems. Section III discusses about the concept of smart university by

\footnotetext{
+ Corresponding author. Tel.: +7727 3132388 .

E-mail address: n.saparkhojayev@almau.edu.kz.
} 
using RFID and NFC technologies and its implementation. Section IV is presenting the results and analysis. Finally, our conclusions and future work directions presented in section V.

\section{Motivation for Implementing Smart System}

The research in [9-10] showed that statistically significant correlation exists between the class attendance and the academic progress of students. The analysis of classroom attendance data gives instructors an insight into potential issues with course progress. At the same time, students are encouraged not to miss their classes if lecture attendance counts towards final grading. Continuous monitoring of attendance may be obligatory for international students in relation to the country visa policy [11], [12]. In Kazakhstan, checking students' attendance is one of the important issues for universities too, because many universities consider students' attendance and while giving the final grade, professors take into account their total number of appearances on classes during the whole semester. This brings to the idea of having some tool to control students' attendance. Moreover, some Kazakhstani universities prefer to use paper sheet for controlling attendance, whereas some universities prefer to use paper sheet for checking students' attendance and after this, fill out these information into a system manually, like Kazakh-British Technical University does. Moreover, some students may call his/her friend as "presence" even though this student is currently absent. After thinking all these issues, authors of the following research paper decided to create a system that makes easier to check students' attendance automatically [13]. In [14], researchers developed mobile attendance checking system based on Android. They have developed such an online system, on which the student will first have to register himself/herself on the app. The information will be routed from the Apache Server to the database. The student will be given a pin and the student can register himself or herself with the pin. In [15], authors proposed a system functional model to manage the student attendance in a more efficient way by utilizing the RFID tags technology. Authors of [16] showed the benefits of building smart attendance checking system based on RFID technology, and results showed that RFID technology saved considerable amount of time and greatly improved the operation efficiency. Finally, after reading some more research work of foreign scientists and researchers [17]-[21], we came up with the idea of implementing such system in Kazakhstan too.

\section{The Concept of Smart University and Its Implementation}

Regarding the implementation, as it was mentioned previously, we have started from implementing the "Students' Attendance Checking System". All classes must have a PC with a connected RFID-reader that can read student RFID-cards, as well as a Web-camera that can take their photos. The camera is meant to prevent a student from giving his/her RFID-card to a classmate who attends the lecture, scanning the other student's RFID-card and to make it appear as if s/he had also attended.

Fig. 1 shows how this attendance-control system works.

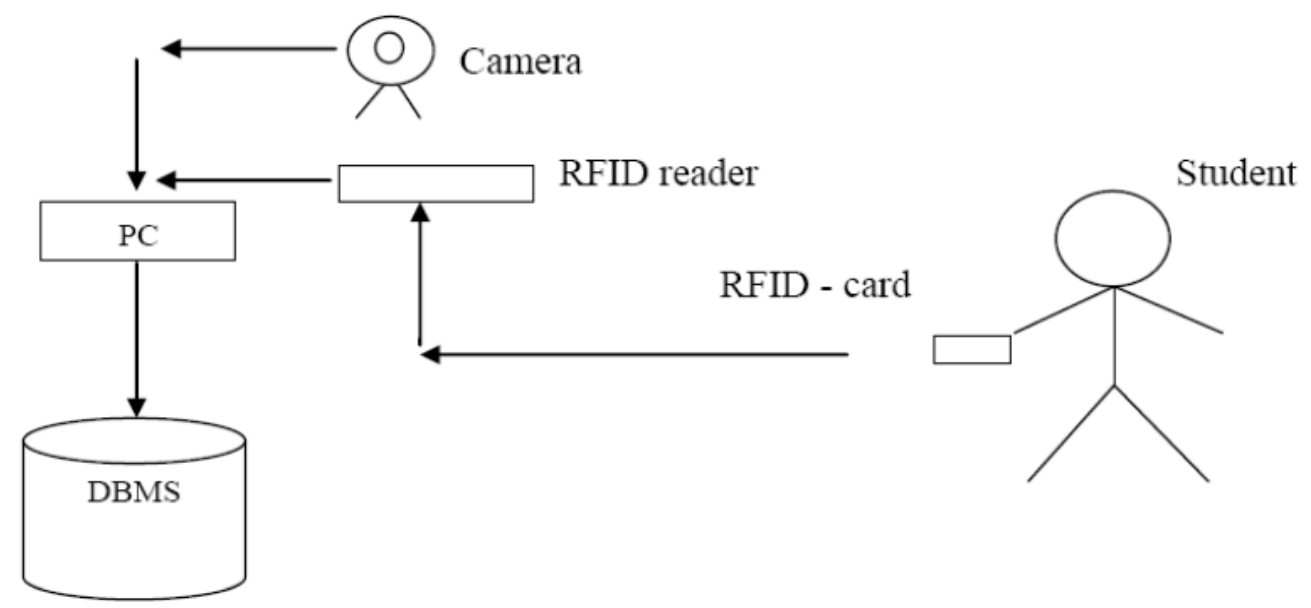

Fig. 1. Architecture of attendance-checking system. 


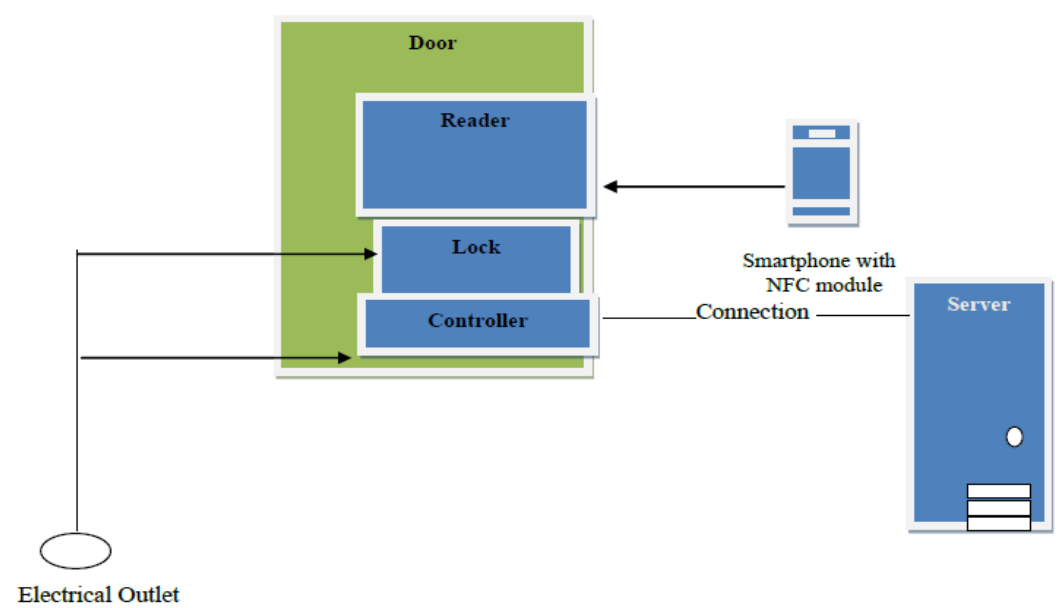

Fig. 2: The overall architecture of access control and management system based on NFC-technology.

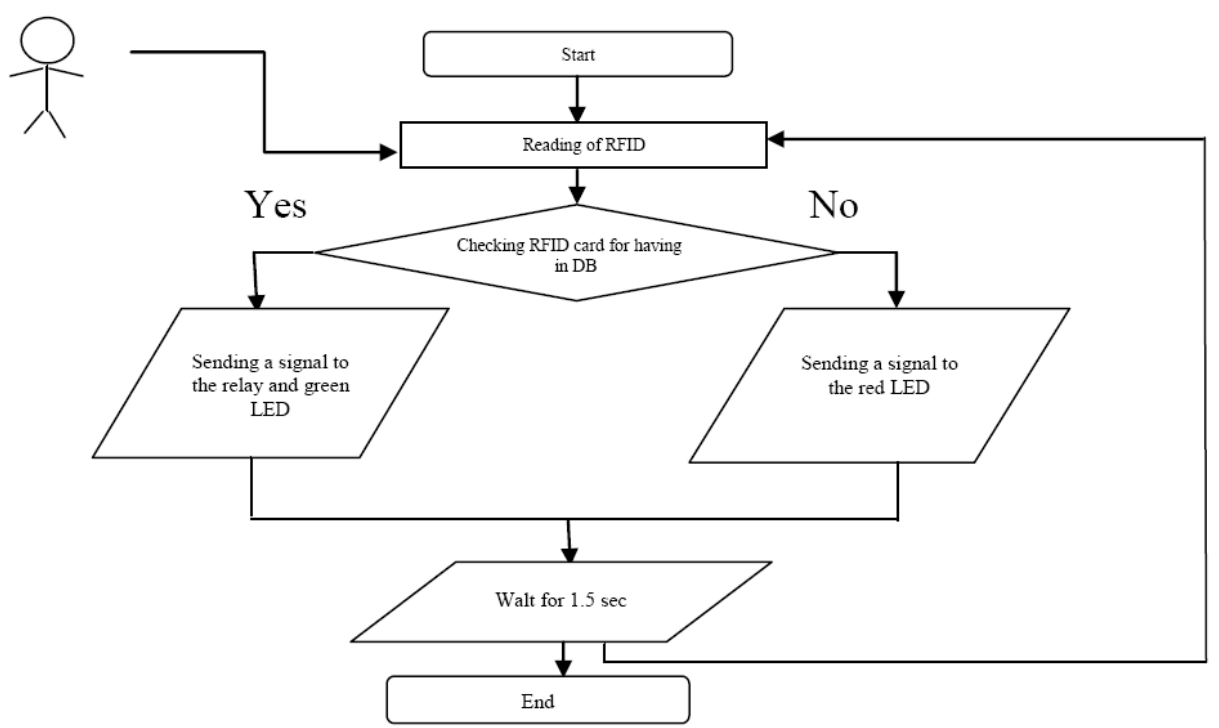

Fig. 3: The workflow of CAS.

After finishing this system, we started analysing about the way of implementing the system for controlling staff arrival and leave time in order to know the total amount of hours that workers spend each day. This system timestamps every swipe of this ID-card so that the system controls entrance and leave times of the person. This system is capable of the following:

- Accurate monthly report of staff attendance and no paperwork for HR department, less problem;

- Reports are saved in secured .PDF format, so that at the end of each month administration will have a nice documented attendance [22].

Later on, we have added new system, which allows authorised users open/close and lock/unlock doors by the use of smart phones. For this system, we have used benefits of NFC- technology that is almost built in every modern smart phones [23].

Next step was in implementing so-called "Computer Access System" (CAS), which is able to allow users to start PC by the use of individual unique RFID card/tag, and to assign which PC's can be used by any users, so that at the end unauthorized person or student cannot start any PC. The most important issue of the use of such system is that this system secures parts of PC from possible steal of its hardware components. Moreover, the data security on the installed hard drives is protected since no one can connect to USB and the only open components of the PC are monitor, keyboard and the mouse [24].

Next, we have implemented the mobile version of students' attendance checking system that is used by Almaty 
Management University. It is well-known fact that today mobile phones are very popular and there are many applications that may be used for different routines of human lives. Generally, our mobile application can perform all operations that appear in Fig. 4.

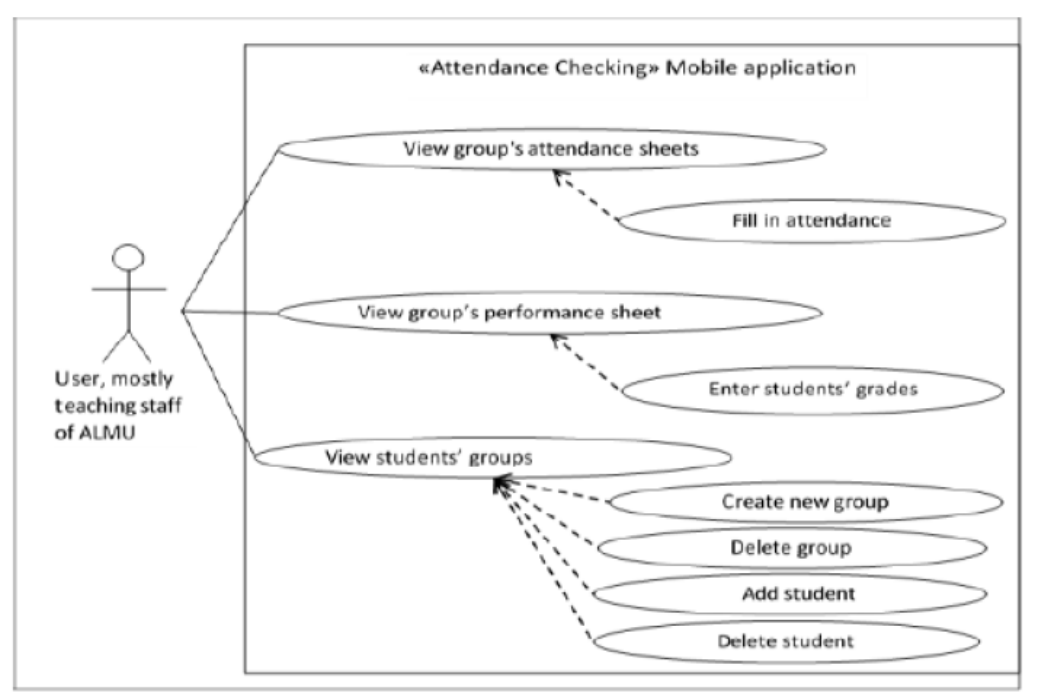

Fig. 4: The diagram of the use of mobile application.

\section{Results and Analysis}

This system is flexible, which means that it may be extended by adding more modules. The cards that have been employed for this specific system are RFID-cards, and the algorithm used has shown stable and reliable results; moreover, this algorithm has secured important data that we have stored on these cards. As RFID-readers, we have used two different reader, namely: Stronglink's SL040A was used for staff control and As RFID-reader, EHUOYAN's YHU638 was used for students' attendance checking. Also, we have used Arduino microcontrollers for connecting lab desktops with RFID-reader and control them remotely with ID-cards.

\section{Conclusions and Future Work}

Smart systems are always in demand and the proposed system requires less paper work. Work is very easy because there is no need of keeping the data in papers. It saves time in generating the accurate results of students' and staff attendance times. Thus, report generation is easy. This system can save huge amount of time and human work.

For the future work, this research should be extended by adding more modules and making some updates or changes. We plan to use GPS and GSM technologies in educational system, and the work that was done in [25] is an inspiration for this project implementation

\section{References}

[1] K. Domdouzis, B. Kumar, and C. Anumba. Radio-Frequency Identification (RFID) applications: A brief introduction. Advanced Engineering Informatics. 2007, 21: 350-355.

[2] D. Nosowitz. Everything you need to know about Near Field Communication. Popular Science. 2011.

[3] C. Le Gal, J. Martin, A. Lux, J. L. Crowley. SmartOffice: design of an intelligent environment. IEEE Intelligent Systems. 2001, 16(4): 60-66.

[4] P. Fuhrer, and D. Guinard. Building a Smart Hospital using RFID technologies. In: P. Fuhrer, et al (eds.). Proc. of ECEH06. Fribourg: 1st European Conference on eHealth (ECEH06). 2006, pp. 1-14.

[5] H. Al Nahas, J. S. Deogun. Radio Frequency Identification Applications in Smart Hospitals. In: H. Al Nahas, et al (eds.). Proc. of 20th IEEE International Symposium. Maribor: Computer-Based Medical Systems - CBMS. 2007, pp. 337-342.

[6] M. Weiser. The computer of the 21st century. Scientific American. 1991, 265(3): 66-75. 
[7] Aqeel-ur-Rehman, A. Z. Abbasi, Z. A. Shaikh. Building a smart university using RFID technology. In: Aqeel-urRehman, et al (eds.). Proc. of the 2008 International Conference on Computer Science and Software Engineering. Wuhan: IEEE Computer Society. 2008, pp. 641-644.

[8] A. Ahmed, A. S. Quraishi, Z. Sattar and Z. B. Alam. RFID based Smart Office. B.S. Engineering, National University of Computer and Emerrging Sciences. Karachi, Pakistan, 2008.

[9] L. Newman-Ford, K. Fitzgibbon, S. Lloyd and S. Thomas. A large-scale investigation into the relationship between attendance and attainment: a study using an innovative, electronic attendance monitoring system. Studies in Higher Education. 2008, 33(6): 699-717.

[10] M. Cred'e, S. G. Roch and U. M. Kieszczynka. Class Attendance in college. A Meta-Analytic Review of the Relationship of Class Attendance with Grades and Student Characteristics. Review of Educational Research. 2010, 80(2): 272-295.

[11] The University of Sheffield. Student Attendance Monitoring — Policy and Guidance for Departments (with effect from 2012-13), 2014. Retrieved from http://www.sheffield.ac.uk/ssd/sam.

[12] University of West London, Student Attendance Monitoring Policy, 2013. Retrieved from http://www.uwl.ac.uk/about-us/policies.

[13] N. Saparkhojayev and S. Guvercin. Attendance Control System based on RFID-technology. IJCSI International Journal of Computer Science Issues. 2012, 9(3): 1694-0814.

[14] B. James, G. D'mello, R.D'souza and J. More. Automated Attendance using Android Devices. IJAIS International Journal of Applied Information Systems. 2015, 8 (6): 21-26.

[15] K.W.Prasetyo and S. Sakaria. Functional Model of RFID-based Students Attendance Management System in Higher Education Institution. Proc. of the First International Conference on Information Technology and Security. Malang: IC-ITECHS. 2014.

[16] A. Agrawal and A. Bansal. Online Attendance Management System Using RFID with Object Counter. International Journal of Information and Computation Technology. 2013, 3 (3): 131-138.

[17] M. Georgina Merlin, S. Jeevitha and K. Nandhini. Human Surveillance and Alert System u sing RFID. IJARECE International Journal of Advanced Research in Electronics and Communication Engineering. 2015, 4(11): 27242729.

[18] A. Samochadin, D. Raychuk, D. Timofeev, and I. Khmelkov. Attendance monitoring as a context-aware service. Proc. of 10th International Conference on Educational Technologies. Istanbul: EDUTE. 2014: pp. 44-48.

[19] A.L. Rekha and H.K. Chethan. Automated Attendance System using Face Recognition through Video Surveillance. International Journal for Technological Research in Engineering. 2014, 1(11):1327-1330.

[20] S. Kadry and K. Smaili. A Design and Implementation of a wireless Iris Recognition Attendance Management System. Information Technology and Control. 2007, 36(3): 323-329.

[21] N. Kar, M. K. Debbarma, A. Saha, and D. R. Pal. Study of Implementing Automated Attendance System Using Face Recognition Technique. International Journal of Computer and Communication Engineering. 2012, 1(2):100-103.

[22] N. Saparkhojayev. RFID-based Staff Control System (SCS) in Kazakhstan. Journal of Physics: Conference Series. 2015, 622(1): 1-6.

[23] N. Saparkhojayev, A. Nurtayev, and G. Baimenshina. Access Control and Management System Based on NFCTechnology by the Use of Smart Phones as Keys. Middle-East Journal of Scientific Research. 2014, 21(7): 11301135 .

[24] N. Saparkhojayev and A. Kurymbayev. Implementation of RFID - Based Computer Access System (CAS) for Kazakhstani University. In: N. Saparkhojayev, et al (eds.). Proc. of 5th International Workshop on Computer Science and Engineering: Information Processing and Control Engineering. Moscow: WCSE 2015-IPCE. 2015.

[25] S.B. Patil and R.M. Walli. Design and Development of fully automatic AT89C52 based low cost embedded system for rail tracking. International Journal of electronic communication and soft computing science and engineering. 2012, 1(1): 9-14. 